\title{
BIOTYPING OF ESCHERICHIA COLI
}

\author{
Pamela B. Crichton and D. C. Old \\ Department of Bacteriology, University of Dundee Medical School, Ninewells Hospital, \\ Dundee DDI $9 S Y$
}

AlthOUGH serotyping of Escherichia coli provides excellent strain differentiation, national reference laboratories are often not able to offer this service because of the expense and labour involved. This is particularly true for strains of $E$. coli isolated from urinary-tract infections. Smaller laboratories, therefore, either use commercially prepared antisera, or prepare their ownwhich may be unsatisfactory, especially if the range of sera is limited, because partial serotyping is unlikely to give sufficient discrimination among strains.

Nevertheless, the importance of accurate strain identification in the determination of management of patients with $E$. coli urinary-tract infections has been well argued by Davies (1977) who characterised strains of $E$. coli by the commercially available API 20E Enterobacteriaceae System (A.P.I. Laboratory Products, Rayleigh, Essex); the 21 standardised biochemical tests give each strain a numerical profile rather than a biotype. However, tests chosen primarily to differentiate among the genera of the Enterobacteriaceae are unlikely to be those that give maximum differentiation of strains of $E$. coli. Furthermore, the system may be unreliable because many enterobacteria give different profiles on repeated testing (Butler, Lobregat and Gavan, 1975).

Bettelheim and Taylor (1969) biotyped strains of E. coli on the basis of decarboxylase tests and the fermentation of 16 carbohydrates but concluded that biotyping was of little value in primary strain identification. However, in view of the success of Davies (1977), we re-examined the biotyping of $E$. coli to try to establish tests that were easy to perform, reproducible and highly discriminatory; we also evaluated the usefulness of the tests in discriminating between strains of $E$. coli isolated from patients.

\section{MATERIALS AND METHODS}

\section{Bacteria}

A total of 917 isolates of $E$. coli was studied. These included: 177 strains selected randomly from the National Collection of Type Cultures (NCTC), London, representing O serogroups 1-162 inclusive, except 67, 72,94,122,159,160 and 161; 97 strains received from Professor W. Brumfitt, Royal Free Hospital, London (B), from patients with persistent or recurrent urinarytract infections; 246 strains (EPEC DU) isolated mainly from 1973 to 1975 in the Bacteriology Department, Ninewells Hospital, Dundee, from the faeces of children less than 2 years old with gastroenteritis; a further 397 strains (Diverse DU) isolated in Dundee from 1976 to 1978, 304 of which were from patients with urinary-tract infections and the remainder from blood cultures, wound swabs and body aspirates or fluids. All strains were stored on Dorset's egg slopes at ambient temperature until subcultured for testing.

\section{Received 21 Feb. 1979; accepted 12 Mar. 1979.}




\section{Culture media}

Nutrient agar $(p \mathrm{H} \mathrm{7.0)}$ and MacConkey agar $(p \mathrm{H} 7.4)$ were prepared according to the instructions of the manufacturer (Oxoid).

Mineral-salts agar. The basic medium contained $\mathrm{K}_{2} \mathrm{HPO}_{4} 7 \mathrm{~g}, \mathrm{KH}_{2} \mathrm{PO}_{4} 3 \mathrm{~g},\left(\mathrm{NH}_{4}\right)_{2} \mathrm{SO}_{4} 1 \mathrm{~g}$, $\mathrm{MgSO}_{4} .7 \mathrm{H}_{2} \mathrm{O} 0.1 \mathrm{~g}$, and Difco Bacto-Agar, $15 \mathrm{~g} /$ litre of deionised water $(p \mathrm{H} 7.0)$. A sterile solution of D-glucose was added to the basal medium at $0.3 \%(w / v)$. Except where otherwise stated, agar media were poured in $20-\mathrm{ml}$ volumes in plastic petri dishes $(8.5 \mathrm{~cm}$ diameter).

Motility medium contained Oxoid Tryptone Water $15 \mathrm{~g}$ and Difco Bacto-Agar $3 \mathrm{~g}$ per litre of deionised water. The molten agar was dispensed, after thorough mixing, in 10-ml amounts in cotton-wool-stoppered test tubes $(15 \times 1.5 \mathrm{~cm})$ and autoclaved.

Aesculin media. Aesculin broth and agar were prepared at $p \mathrm{H} 7.4$ according to the methods of Cowan (1974). The broth was dispensed in 5-ml amounts in screw-capped 25-ml bottles.

Sugar peptone waters. The basal medium contained Oxoid Peptone Water $15 \mathrm{~g}$ and, as indicator, bromocresol purple $0.02 \mathrm{~g}$ per litre of deionised water. The following carbohydrates were prepared as $10 \%$ (w/v) solutions in deionised water: adonitol, L-arabinose, D-cellobiose, dulcitol, meso-inositol, lactose, maltose, D-raffinose, L-rhamnose, salicin, D-sorbitol, L-sorbose, sucrose, $\mathrm{D}$-trehalose, and $\mathrm{D}$-xylose; all were steamed for $1 \mathrm{~h}$ at $100^{\circ} \mathrm{C}$ and were added to the sterile basal medium at a final concentration of $0.5 \%(\mathrm{w} / \mathrm{v})$ and the completed media were dispensed in 4-ml amounts in sterile, screw-capped 6-ml bottles and steamed at $100^{\circ} \mathrm{C}$ for 30 $\min$.

Decarboxylase medium. The basal medium contained Oxoid Bacteriological Peptone $5 \mathrm{~g}$, Oxoid Yeast Extract $3 \mathrm{~g}$, D-glucose $1 \mathrm{~g}$ and bromocresol purple $0.02 \mathrm{~g}$ per litre of deionised water; L-arginine monohydrochloride, L-lysine monohydrochloride or L-ornithine monohydrochloride were added to the basal medium at a final concentration of $0.5 \%(w / v)$. Basal medium without additions served as control. The media, adjusted to $p \mathrm{H} 6.7$, were dispensed in 5-ml amounts in screw-capped 6-ml bottles.

Except where otherwise stated, all media were autoclaved at $121^{\circ} \mathrm{C}$ for $15 \mathrm{~min}$.

\section{Inoculation and reading}

Each stock culture was plated on MacConkey agar and checked for purity after incubation at $37^{\circ} \mathrm{C}$ for $24 \mathrm{~h}$. A single colony was spread on a nutrient-agar plate which was incubated at $37^{\circ} \mathrm{C}$ for $24 \mathrm{~h}$. The resulting bacterial growth was suspended in physiological saline $(\mathrm{NaCl} 8.5 \mathrm{~g}$ per litre of deionised water) to a density of $c .10^{9}$ bacteria $/ \mathrm{ml}$ and the biotyping media were inoculated with the suspension either with a single drop $(0.02 \mathrm{ml})$ from a capillary pipette or by means of an inoculating wire. All media were incubated at $37^{\circ} \mathrm{C}$.

Fermentation tests were observed daily for 7 days for acid production (indicator change from purple to yellow). Strains that were genotypically non-fermenting often produced late-positive results due to the selection and growth of fermenting mutants, and we therefore identified for each substrate a definitive time of reading (24-72 h) which gave optimal separation of the genotypically fermenting types from the non-fermenting types, following the procedures of Duguid et al. (1975). The decarboxylase tests were read as positive when the medium became alkaline (purple) at $48 \mathrm{~h}$ and the amino-acid-free medium remained acid (yellow). Tests for aesculin hydrolysis were read at 1,2 and 3 days for the production of a blue-black colour in broth, or for growth with blue-black papillae and a dark-brown precipitate on agar. Glucosemineral-salts medium was examined for the presence or absence of growth at $24 \mathrm{~h}$ and the growth-factor requirements of auxotrophs were determined by the methods of Meynell and Meynell (1965). Strains inoculated in motility medium and incubated at $37^{\circ} \mathrm{C}$ were judged as motile, indicated by + , when there was spreading growth from the central stab inoculum at $24 \mathrm{~h}$. Strains that gave flares of growth from the stab line when incubation was continued at $30^{\circ} \mathrm{C}$ for a further $48 \mathrm{~h}$ were recorded as late motile, indicated by $(+)$.

\section{Serological analysis}

E. coli agglutinating antisera. The antisera (Wellcome Reagents Ltd, Beckenham, Kent) 
were stored throughout at $4^{\circ} \mathrm{C}$. Enteropathogenic $E$. coli antisera were: Wellcome Polyvalent 2 and its components 026:K60(B6), 055:K59(B5), 0111:K58(B4), 0119:K69(B14), 0126: K71(B16); Polyvalent 3 and its components 086:K61(B7), 0114:K90(B), 0125:K70(B15), 0127:K63(B8), 0128:K67(B12); and Polyvalent 4 and its components 044:K74(L), 0112:K66(B11), 0124:K 72(B17), 0142:K86(B). Urinary E. coli antisera were: Wellcome Polyvalent $A$ and its components 01, 02, 04, 05 and 06; and Polyvalent $B$ and its components 09, 011, 018, 039 and 075.

Saline suspensions of bacteria from nutrient-agar cultures were held at $100^{\circ} \mathrm{C}$ for $1 \mathrm{~h}$, and the bacteria resuspended in saline to a density of $c .5 \times 10^{8}$ bacteria $/ \mathrm{ml}$. Suspensions were screened against the commercial sera by slide-agglutination tests. All positive slide-agglutination results were confirmed by quantitative tube-agglutination tests performed according to the manufacturer's instructions, except that incubation was at $37^{\circ} \mathrm{C}$ for $4 \mathrm{~h}$ and development was overnight at $4^{\circ} \mathrm{C}$. Three $E$. coli strains (patient MG, table V) were serotyped as 0157:K? at the Enteric Reference Laboratory, London.

\section{RESULTS}

Significant tests in epidemiological studies should be reliable, i.e., give identical results on repeated testing of the same strain, and should be highly discriminatory. Discriminating ability is good when a large number of types is distinguished but poor if a large proportion of the strains falls into a single or a few types.

\section{Fermentation of carbohydrates}

A preliminary survey was made of the ability of 274 strains of $E$. coli to ferment 15 of the 16 carbohydrates used by Bettelheim and Taylor (1969). Difficulties in interpreting the tests for the fermentation of glycerol led us to discard this substrate at an early stage. Results of the survey of the randomly selected NCTC strains (177) and the clinically selected B series (97) showed that nine of the 15 substrates tested gave poor differentiation of the strains when read at the definitive times. Thus, at the definitive time of 1 day, the majority of the strains fermented L-arabinose $(100 \%)$, lactose $(96 \%)$, maltose $(96 \%)$, D-sorbitol $(96 \%)$, D-trehalose $(99 \%)$ and D-xylose $(98 \%)$ and did not ferment D-cellobiose $(99 \%)$ and $m$-inositol $(100 \%)$. L-rhamnose gave moderate discrimination by detecting $15 \%$ of the minority, non-fermenting type. On the other hand, the substrates dulcitol $(65 \%+)$, D-raffinose $(50 \%+)$, salicin $(59 \%+)$, L-sorbose $(48 \%+)$ and sucrose $(46 \%+)$ afforded good differentiation into fermenting and non-fermenting types. Because the results for adonitol fermentation were equivocal, we examined another 246 strains (a total of 520 strains) and showed that this test, which detected only $5 \%$ of the minority fermenting type, was poorly discriminatory. Adonitol fermentation was not, therefore, further investigated.

A further 643 E. coli strains, the DU series, were examined for their ability to ferment dulcitol, raffinose, rhamnose, salicin, sorbose, and sucrose (table I). Good differentiation of these 643 strains into fermenting and non-fermenting types was achieved. There were some minor differences in the percentage of strains positive with some substrates in the different groups examined. 
TABLE I

Carbohydrates fermented by strains of Escherichia coli

\begin{tabular}{|c|c|c|c|c|c|}
\hline \multirow[b]{2}{*}{$\begin{array}{l}\text { Carbohydrate } \\
\text { tested }\end{array}$} & \multicolumn{5}{|c|}{$\begin{array}{l}\text { Percentage of strains positive from indicated source } \\
\text { (number examined) }\end{array}$} \\
\hline & $\begin{array}{l}\text { NCTC } \\
(177)\end{array}$ & $\begin{array}{l}\text { B } \\
(97)\end{array}$ & $\begin{array}{l}\text { EPEC DU } \\
\quad(246)\end{array}$ & $\begin{array}{l}\text { Diverse DU } \\
\quad(397)\end{array}$ & All \\
\hline $\begin{array}{l}\text { Adonitol } \\
\text { L-Arabinose } \\
\text { D-Cellobiose } \\
\text { Dulcitol } \\
m \text {-Inositol } \\
\text { Lactose } \\
\text { Maltose } \\
\text { D-Raffinose } \\
\text { L-Rhamnose } \\
\text { Salicin } \\
\text { D-Sorbitol } \\
\text { L-Sorbose } \\
\text { Sucrose } \\
\text { D-Trehalose } \\
\text { D-Xylose }\end{array}$ & $\begin{array}{r}10 \\
100 \\
2 \\
61 \\
1 \\
96 \\
94 \\
48 \\
82 \\
59 \\
94 \\
31 \\
41 \\
98 \\
97\end{array}$ & $\begin{array}{r}3 \\
100 \\
0 \\
72 \\
0 \\
96 \\
100 \\
54 \\
92 \\
60 \\
100 \\
77 \\
56 \\
99 \\
100\end{array}$ & $\begin{array}{c}71 \\
\ldots \\
\ldots \\
\ldots \\
81 \\
84 \\
43 \\
\ldots \\
47 \\
80 \\
\ldots\end{array}$ & $\begin{array}{c}71 \\
\ldots \\
\ldots \\
\ldots \\
48 \\
91 \\
59 \\
79 \\
72 \\
43 \\
\ldots \\
\ldots\end{array}$ & $\begin{array}{r}6 \\
100 \\
1 \\
69 \\
0 \\
96 \\
96 \\
57 \\
87 \\
55 \\
96 \\
58 \\
54 \\
99 \\
98\end{array}$ \\
\hline
\end{tabular}

NCTC $=$ National Collection of Type Cultures;

B $=$ Professor W. Brumfitt;

EPEC DU $=$ From children with gastroenteritis, University of Dundee.

Diverse DU = various sources, University of Dundee;

$\ldots=$ not tested.

Sucrose and raffinose fermentation. Regardless of the group of strains examined, there was a close correlation of the ability of strains to ferment sucrose and raffinose: most strains were either $\mathrm{Suc}^{+} \mathrm{Raf}^{+}$, i.e., fermented both, or were Suc$^{-}$Raf $^{-}$, i.e., fermented neither. For example, among the 177 NCTC strains, 92 were $\mathrm{Suc}^{-} \mathrm{Raf}^{-}$and 72 were Suc ${ }^{+} \mathrm{Raf}^{+}$, whereas only 12 were $\mathrm{Suc}^{-} \mathrm{Raf}^{+}$and one Suc ${ }^{+} \mathrm{Raf}^{-}$.

Biotyping with six carbohydrates. Table II shows the results obtained when strains of $E$. coli isolated on repeated occasions from children with gastroenteritis were tested with the above six substrates and illustrates how well biotyping detected similarities or differences among strains of $E$. coli. For example, all of five isolates of $E$. coli $\mathrm{O} 128$ obtained from patient SW during the 9 months from 30 Jan. to 25 Oct. 1973 , and representing probably a single clone from this child's faeces, werc of the same biotype, and fermented all substrates except sorbose. Similarly, all of five isolates of $E$. coli 055 obtained during 14 days from child DM belonged to the same biotype and did not ferment salicin or rhamnose. Six isolates of $E$. coli 055 obtained from patient MA during a 20-day period were of the same biotype. This pattern was the same as that found for the $E$. coli O55 strains from patient DM but not all strains of this serogroup have this biotype pattern (P.B. Crichton and D.C. Old, unpublished results). A serologically untypable isolate from patient MA isolated on 14 Sept. 1973 showed a biotype profile distinctly different from the pattern of the 
TABLE II

Fermentation patterns and $O$ serogroups of strains of $E$. coli isolated from children with gastroenteritis

\begin{tabular}{|c|c|c|c|c|c|c|c|c|}
\hline \multirow[b]{2}{*}{ Patient } & \multirow{2}{*}{$\begin{array}{l}\text { Strain } \\
\text { isolated on }\end{array}$} & \multicolumn{6}{|c|}{ Fermentation of } & \multirow{2}{*}{$\underset{\text { group }}{\mathbf{O}}$} \\
\hline & & dulcitol & raffinose & salicin & sorbose & sucrose & rhamnose & \\
\hline SW & $\begin{array}{r}30 \text { Jan. } 73 \\
20 \text { Jul. } 73 \\
23 \text { Aug. } 73 \\
26 \text { Sep. } 73 \\
25 \text { Oct. } 73\end{array}$ & $\begin{array}{l}+ \\
+ \\
+ \\
+ \\
+\end{array}$ & $\begin{array}{l}+ \\
+ \\
+ \\
+ \\
+\end{array}$ & $\begin{array}{l}+ \\
+ \\
+ \\
+ \\
+\end{array}$ & $\begin{array}{l}- \\
- \\
- \\
-\end{array}$ & $\begin{array}{l}+ \\
+ \\
+ \\
+ \\
+\end{array}$ & $\begin{array}{l}+ \\
+ \\
+ \\
+ \\
+\end{array}$ & $\begin{array}{l}128 \\
128 \\
128 \\
128 \\
128\end{array}$ \\
\hline DM & $\begin{array}{r}6 \text { Feb. } 75 \\
6 \text { Feb. } 75 \\
12 \text { Feb. } 75 \\
17 \text { Feb. } 75 \\
19 \text { Feb. } 75\end{array}$ & $\begin{array}{l}+ \\
+ \\
+ \\
+ \\
+\end{array}$ & $\begin{array}{l}+ \\
+ \\
+ \\
+ \\
+\end{array}$ & $\begin{array}{l}- \\
- \\
- \\
-\end{array}$ & $\begin{array}{l}+ \\
+ \\
+ \\
+ \\
+\end{array}$ & $\begin{array}{l}+ \\
+ \\
+ \\
+ \\
+\end{array}$ & $\begin{array}{l}- \\
\overline{-} \\
\overline{-}\end{array}$ & $\begin{array}{l}55 \\
55 \\
55 \\
55 \\
55\end{array}$ \\
\hline MA & $\begin{array}{r}3 \text { Sep. } 73 \\
7 \text { Sep. } 73 \\
10 \text { Sep. 73 } \\
12 \text { Sep. 73 } \\
14 \text { Sep. } 73 \\
20 \text { Sep. } 73 \\
\text { 22 Sep. } 73\end{array}$ & $\begin{array}{l}+ \\
+ \\
+ \\
+ \\
+ \\
+ \\
+\end{array}$ & $\begin{array}{l}+ \\
+ \\
+ \\
+ \\
+ \\
+ \\
+\end{array}$ & $\begin{array}{l}- \\
\overline{-} \\
\overline{-} \\
+ \\
- \\
-\end{array}$ & $\begin{array}{l}+ \\
+ \\
+ \\
+ \\
+ \\
+ \\
+\end{array}$ & $\begin{array}{l}+ \\
+ \\
+ \\
+ \\
+ \\
+ \\
+\end{array}$ & $\begin{array}{l}- \\
- \\
- \\
\overline{+} \\
- \\
-\end{array}$ & $\begin{array}{r}55 \\
55 \\
55 \\
55 \\
\text { NT } \\
55 \\
55\end{array}$ \\
\hline DG & $\begin{array}{l}19 \text { Jul. } 73 \\
21 \text { Jul. } 73 \\
23 \text { Jul. } 73 \\
26 \text { Jul. } 73 \\
27 \text { Jul. } 73 \\
28 \text { Jul. } 73\end{array}$ & $\begin{array}{l}+ \\
+ \\
+ \\
+ \\
+ \\
+\end{array}$ & $\begin{array}{l}+ \\
+ \\
+ \\
+ \\
+ \\
+\end{array}$ & $\begin{array}{l}- \\
+ \\
+ \\
- \\
+ \\
+\end{array}$ & $\begin{array}{l}+ \\
+ \\
+ \\
+ \\
+ \\
+\end{array}$ & $\begin{array}{l}+ \\
+ \\
+ \\
+ \\
+ \\
+\end{array}$ & $\begin{array}{l}+ \\
+ \\
+ \\
+ \\
+ \\
+\end{array}$ & $\begin{array}{l}119 \\
119 \\
119 \\
119 \\
119 \\
119\end{array}$ \\
\hline KD & $\begin{array}{l}30 \text { Oct. } 73 \\
30 \text { Oct. } 73 \\
3 \text { Nov. } 73 \\
6 \text { Nov. } 73\end{array}$ & $\begin{array}{l}- \\
- \\
-\end{array}$ & $\begin{array}{l}+ \\
+ \\
+ \\
+\end{array}$ & $\begin{array}{l}+ \\
\overline{-} \\
+\end{array}$ & $\begin{array}{l}+^{*} \\
-^{*} \\
-^{*} \\
+^{*}\end{array}$ & $\begin{array}{l}+ \\
+ \\
+ \\
+\end{array}$ & $\begin{array}{l}+ \\
+ \\
+ \\
+\end{array}$ & $\begin{array}{l}128 \\
128 \\
128 \\
128\end{array}$ \\
\hline SM & $\begin{array}{r}\text { 19 Jun. } 74 \\
\text { 3 Jul. } 74 \\
5 \text { Jul. } 74 \\
5 \text { Jul. } 74 \\
5 \text { Jul. } 74 \\
9 \text { Jul. } 74\end{array}$ & $\begin{array}{l}\overline{+} \\
\overline{-} \\
\overline{-} \\
\overline{-}\end{array}$ & $\begin{array}{l}- \\
+ \\
+ \\
+ \\
+ \\
+\end{array}$ & $\begin{array}{l} \pm \\
- \\
- \\
- \\
-\end{array}$ & $\begin{array}{l}- \\
+ \\
+ \\
- \\
-\end{array}$ & $\begin{array}{l}- \\
+ \\
+ \\
+ \\
+ \\
+\end{array}$ & $\begin{array}{l}+ \\
+ \\
+ \\
+ \\
+ \\
+\end{array}$ & $\begin{array}{l}111 \\
\text { NT } \\
\text { NT } \\
128 \\
128 \\
128\end{array}$ \\
\hline
\end{tabular}

$+=$ Positive reaction; $-=$ negative reaction; $N T=$ not typable with the available antisera.

The sorbose-fermenting strains isolated on 30 Oct. and 6 Nov. fermented adonitol in 1 day whereas the two sorbose-non-fermenting strains did not.

O55 strains in all six biotype characters. Patient DG yielded six isolates of $E$. coli from 19 to 28 July 1973; all were of serogroup O119 and all fermented dulcitol, raffinose, sucrose, sorbose, and rhamnose. Two were salicin fermenters and two were salicin non-fermenters. Tests with salicin were difficult to read; the reasons for this are discussed later.

Patient KD illustrates another important point. Four isolates of serogroup 0128 cultured from this child's faeces from 30 Oct. to 6 Nov. 1973 belonged to two different biotypes: one fermented all substrates except dulcitol; the other did not ferment dulcitol, salicin or sorbose. As indicated above, tests with salicin may be difficult to read but sorbose fermentation is a very reliable test and there are no problems in its interpretation. At this stage, 
therefore, these results must be taken to mean that biotyping either differentiated two distinct biotypes of $E$. coli $\mathrm{O} 128$ in this child's faeces over this short period of time or that a single clone with significant biotype variability was present.

Finally, from 19 June to 5 July 1974, three isolates of E. coli were obtained from patient SM, one of serogroup O111 and two that were not typable with our antisera; the biotype of each was different. From 5 to 9 July another three isolates of $E$. coli were cultured from this child's faeces; all belonged to serogroup $\mathrm{O} 128$ and to a biotype quite different from the above three biotypes.

Thus, provided that care was taken to differentiate between prompt-fermenting and late-fermenting strains arising by mutation from genotypically non-fermenting ones, biotyping results from the fermentation of dulcitol (at 2 days), raffinose ( 3 days), rhamnose (1 day), salicin ( 3 days), sorbose (1 day) and sucrose ( 3 days) were shown in this survey to be as reliable for strain differentiation as $\mathrm{O}$ serotyping.

\section{Other discriminatory tests}

To expand the biotype profiles, we investigated other substrates and tests that, from a review of the literature, might have been expected to afford good differentiation. These were tests for arginine dihydrolase, for lysine and ornithine decarboxylases, for aesculin hydrolysis, for prototrophy and for motility. Table III summarises our results for 671 strains of $E$. coli from different sources. It will be noted that there are no results for the argininedihydrolase test, which was abandoned at an early stage because many strains were weakly positive at any time from 2 to 6 days; it was difficult, therefore, to separate positive from negative types.

The decarboxylase tests were easy to perform and to read, and were discriminatory, although ornithine differentiated more strains $(62 \%+: 38 \%-)$ than lysine $(91 \%+: 9 \%-)$ (table III). Aesculin hydrolysis appeared to be a useful test, differentiating strains optimally $(52 \%+: 48 \%-)$, but there were small differences in the results obtained by the two test methods. It should be

TABLE III

Results of other tests on strains of E. coli

\begin{tabular}{l|cccc}
\hline & \multicolumn{4}{c}{$\begin{array}{c}\text { Percentage of strains positive from indicated source } \\
\text { (number examined) }\end{array}$} \\
\cline { 2 - 5 } \multicolumn{1}{c}{ Test for } & $\begin{array}{c}\text { NCTC } \\
(177)\end{array}$ & $\begin{array}{c}\text { B } \\
(97)\end{array}$ & $\begin{array}{c}\text { Diverse DU } \\
(397)\end{array}$ & $\begin{array}{c}(671) \\
\text { All }\end{array}$ \\
\hline $\begin{array}{l}\text { L-lysine decarboxylase } \\
\text { L-ornithine decarboxylase }\end{array}$ & 88 & 90 & 93 & 91 \\
$\begin{array}{l}\text { aesculin hydrolysis } \\
\text { prototrophy } \\
\text { motility }\end{array}$ & 51 & 68 & 70 & 62 \\
& 88 & 51 & 53 & 52 \\
& 66 & 43 & 88 & 86 \\
\end{tabular}

Footnotes as in table I. 
noted that strains classified by us as positive gave negative results when tested by the method recommended by Edberg, Pittman and Singer (1977). Of the 177 NCTC strains, 161 gave the same result for aesculin and for salicin regardless of the method used for aesculin testing. Fifteen strains that were positive on aesculin agar after $24 \mathrm{~h}$ were also positive in aesculin broth and salicin peptone water. Positive results on aesculin agar were not given by salicin non-fermenters, and the nine strains that gave a positive aesculin result only in aesculin broth but not on aesculin agar were found to be weakly active against salicin, i.e., fermented salicin in 2-3 days.

Tests for prototrophy and the identification of the growth-factor requirements of auxotrophic strains were easy to read and perform, and differentiated $14 \%$ of the minority, auxotrophic type. The test for motility at $37^{\circ} \mathrm{C}$ discriminated strains well $(58 \%+: 42 \%-)$ but care was necessary in its interpretation. When incubation of the semisolid agar was continued at $30^{\circ} \mathrm{C}$, many strains showed flares of growth from the inoculum stab and might have been motile mutants. When allowance was made for these late positive strains, the ratio of types was $(63 \%+$ and $(+): 37 \%-)$.

A total of 671 strains of $E$. coli was biotyped by tests for the fermentation of dulcitol, raffinose, rhamnose, sorbose, and sucrose; for aesculin (and salicin) hydrolysis; for decarboxylation of lysine and ornithine; for prototrophy; and for motility. The results for these tests are shown in tables I and III.

Other observations. On occasion, we examined in a single specimen, usually of urine from a patient with long-term urinary-tract infection, 20 of the colonies of $E$. coli present on the primary plating medium. All of the colonies tested had the same biotype profile and this finding was regardless of whether or not different colonial morphologies had been noted. When many colonies of strains of $E$. coli stored on Dorset's egg slants were retested after storage for months or years, the biotype of the retested culture was always the same as that originally identified for the strain when isolated from a fresh specimen.

\section{The potential usefulness of biotyping in clinical practice}

Table IV shows the biotype profiles of cultures of $E$. coli isolated from the urine of nine patients with long-term urinary-tract infections; these are 22 of the 97 E. coli cultures received from Professor W. Brumfitt, who had classified his patients as having either persistent infection, i.e., when strains of the same $O$ serogroup were isolated from the patient's urine on several occasions during a period of months, or recurrent infection, i.e., when strains of different $\mathrm{O}$ serogroups were isolated during a similar period. In four patients considered to have persistent infection due to $E$. coli of serogroup 075 ( 3 patients) or $\mathrm{O} 39$ ( 1 patient) over a period of 2-8 months, the biotype of each member of the pair of isolates was the same; it is interesting to note, however, that the biotypes of the three pairs that were 075 were distinct. The advantages of biotyping were demonstrated with the patients $G(L 1)$ and J(L63) (table IV). The autoagglu- 


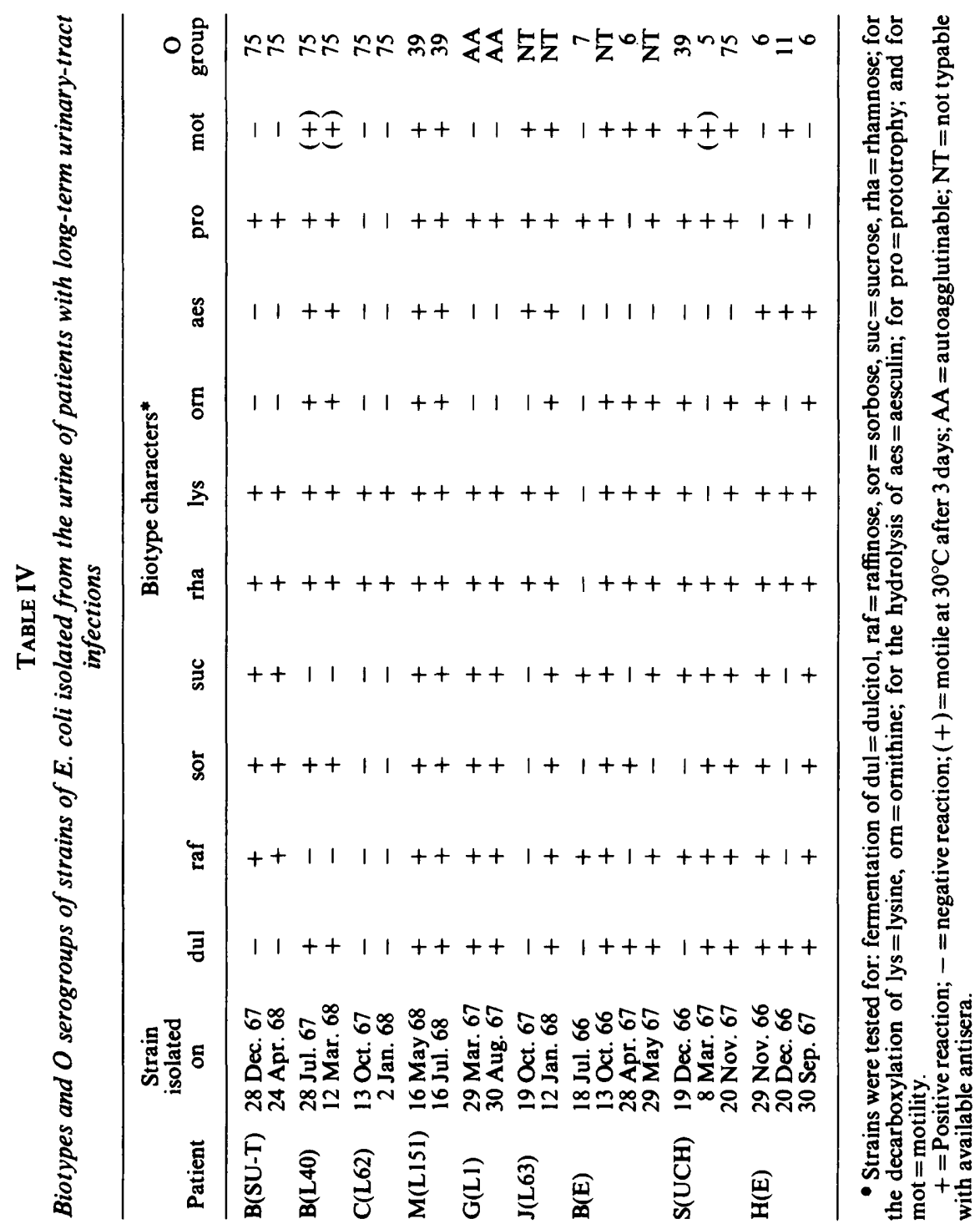




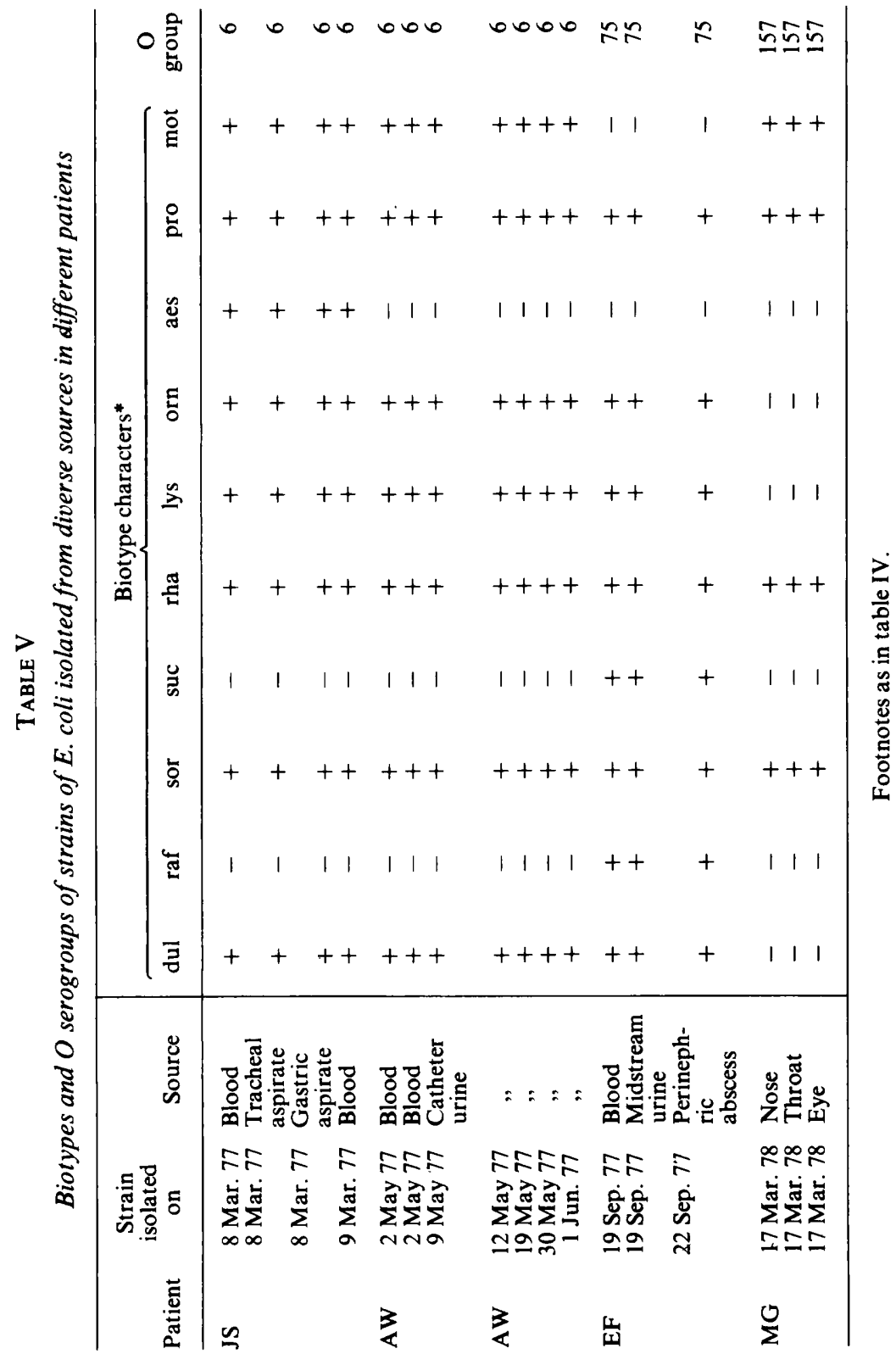


tinable strains from patient $G(L 1)$, isolated 5 months apart, had the same biotype and probably represented persistent infection due to the same strain whereas the non-serotypable strains from patient $J(L 63)$ were of biotypes that differed in five of the ten characters tested and probably represented infections by two distinct strains of $E$. coli.

Among patients considered to have repeated re-infections because of $\mathrm{O}$ serogroup differences in the strains of $E$. coli isolated, patient $\mathrm{B}(\mathrm{E})$ produced over a 10-month period four isolates of $E$. coli, two of which were not serotypable. The biotypes were different for each of the four isolates. Patient $\mathrm{S}(\mathrm{UCH})$ who yielded three isolates of $E$. coli with different $\mathrm{O}$ serogroups appeared to have been infected by three distinct strains of different biotypes. In patient H(E), the strains of O6 serogroup isolated in Nov. 1966 and Sept. 1967 were of the same biotype but that of serogroup O11 isolated in Dec. 1966 was of a quite different biotype. Thus, biotyping did not contradict the conclusions based on serotyping and was invaluable for cases in which serotyping could not be used, because the strains were either autoagglutinable or were untypable with the limited range of antisera available.

Biotyping proved equally worthwhile with other patients who had infections due to E. coli (table V). For example, from JS, a 57-year-old patient who had collapsed after a vagotomy and pyloroplasty, E. coli was cultured over 2 days from venous blood and tracheal and gastric aspirates. These four isolates were of the same biotype and belonged to serogroup O6. AW was a 71-yearold patient with pyrexia and acute renal failure. Duplicate blood cultures on 2 May 1977 and five catheter urines collected from this patient from 9 May to 1 June all yielded $E$. coli. These seven isolates were of the same biotype (table V) and all were serogroup O6. E. coli was cultured from venous blood and mid-stream urine taken on 19 Sept. 1977 from EF, a 77-year-old female patient with pyrexia and altering heart murmurs. At necropsy on 22 Sept. 1977 this patient was found to have a perinephric abscess from which $E$. coli was cultured. All three isolates were of the same biotype (table V) and later were found to belong to serogroup 075 . Finally, eye, nose and throat swabs taken on the same day from a 9-day-old baby (MG) with sticky eyes, all yielded $E$. coli of the same biotype; all three were serotyped as O157:K?

\section{Discussion}

The epidemiological value of different methods of distinguishing types of $E$. coli depends on the reliability of the tests and their ease of performance. Davies (1977) attempted to biotype strains of E. coli with the API 20E Enterobacteriaceae System but because 16 of the 21 tests in that system gave little or no discrimination, in that most of the strains were either positive or negative with regard to a particular character, we sought other biotyping tests that separated strains optimally, i.e., $50 \%+: 50 \%-$. Considerable departure from the optimum, which is rarely achieved, is acceptable if the results so obtained are stable.

Our results show that tests such as the fermentation of adonitol, L-ara- 
binose, D-cellobiose, meso-inositol, lactose, maltose, D-sorbitol, D-trehalose and D-xylose differentiated too few strains of the minority type $(<6 \%)$ to justify their use for the biotyping of strains of $E$. coli though these are helpful in the primary identification of strains as $E$. coli. On the other hand, our results suggested that the tests for the decarboxylation of L-ornithine and for the fermentation of dulcitol, L-sorbose, D-raffinose, and sucrose were highly discriminatory. The close correlation between the results for the fermentation of sucrose and raffinose and the demonstration that $\mathrm{Suc}^{+} \mathrm{Raf}^{-}$and Suc ${ }^{-} \mathrm{Raf}^{+}$ phenotypes were rare are in agreement with the findings of other workers (Årr, Perènyi and Novàk, 1970; Cornelis, Luke and Richmond, 1978). Detailed discussions on the activity of enzymes responsible for the hydrolysis of these substrates are available in the works of Àrr et al., 1970; Buissière, Coynault and Le Minor, 1977; Cornelis et al., 1978. Other tests giving useful information were those for the fermentation of L-rhamnose, for motility, for prototrophy, and for the decarboxylation of L-lysine which discriminates at about the lowest acceptable level $(91 \%+: 9 \%-)$.

Tests of doubtful value were those for the hydrolysis of aesculin and salicin. The same $\beta$-glucosidase is probably responsible for the hydrolysis of these two structurally related substrates and, on the whole, there was reasonable correlation between aesculin hydrolysis and salicin fermentation. With the latter test, however, we often found it difficult to interpret accurately the time of salicin fermentation even when dealing with replicate cultures inoculated from the same colony. Again, identical results might have been expected for aesculin hydrolysis when tests were made on agar and in peptone-based liquid media but there were discrepancies. Although aesculin hydrolysis has been useful for the differentiation of genera within the family Enterobacteriaceae, there have been conflicting reports about its usefulness for $E$. coli. In a recent review, Miskin and Edberg (1978) concluded that the discrepancies found with E. coli in regard to the hydrolysis of these substrates were probably due to the inducible nature of the $\beta$-glucosidase and considered that such inconsistencies were due to differences in inoculum size. We have confirmed their findings and found that none of our isolates of $E$. coli hydrolysed aesculin within $24 \mathrm{~h}$ whereas continued incubation to $72 \mathrm{~h}$ resulted in increasing numbers of positive cultures. In addition, when strains in which the $\beta$-glucosidase was inducible were incubated in aesculin minimal medium, variants were produced that gave constitutive growth on aesculin agar and prompt fermentation of salicin. However, in view of the lack of reproducibility of tests with salicin and aesculin in liquid media, we have discarded them. The use of aesculin agar allows estimation of the percentage of cells in an E. coli population capable of aesculin hydrolysis and probably separates weak, inducible strains from nonhydrolysers but still requires great care in its interpretation.

We would, therefore, recommend the use of the following tests for maximum discrimination: fermentation of dulcitol, sorbose, raffinose or sucrose or both (we have relied more on the former), and the decarboxylation of ornithine; further discrimination at a lower level was achieved with the tests for fermentation of rhamnose, motility, prototrophy, and decarboxylation of 
lysine. Other workers have recorded the usefulness of some of our recommended substrates. Thus, fermentation of dulcitol, rhamnose, and sucrose were used by Mushin and Ashburner (1964); fermentation of dulcitol, rhamnose and sucrose, and decarboxylation of lysine and ornithine by Sakazaki, Tamura and Nakamura (1974); fermentation of dulcitol, raffinose, rhamnose, sorbose, and sucrose by Bettelheim et al. (1974); fermentation of dulcitol, raffinose, rhamnose, and sucrose by van der Waaij et al. (1975); and fermentation of dulcitol, raffinose, rhamnose, sucrose and lysine, ornithine decarboxylation, and motility by Magalhães and Vance (1978). Each group, however, included in their schemes other substrates which, though useful for primary identification, afforded little strain discrimination.

We have used our biotyping tests for the routine subtyping of strains of $E$. coli isolated from the urines of patients with long-term urinary-tract infections (table IV) and from other sites (table V) and have found biotype profiles to be as reliable as partial serotyping for the characterisation of strains. Indeed, because all strains are biotypable, it may be the method of choice when strains are serologically untypable or autoagglutinable. For smaller laboratories in which full serotype analysis is not practicable, biotyping might well be the best differential typing method for cultures already identified as $E$. coli.

The reliability of our biotyping system was demonstrated by our observations that (1) biotype profiles were the same when large numbers of colonies from a pure culture were tested and (2) repeated testing of a single-colony line and testing after storage on non-selective media for long periods gave the same biotype profiles. Stability of biotype on storage means that biotyping can be used for prospective and retrospective studies. The unreliability of biotyping, claimed by some other workers, might have been due to inability to identify definitive times of reading tests. We did not overlook this point and in our hands biotyping, with the exception of the tests for aesculin and salicin, was not subject to minor variations in technique.

We prefer not to give each biotype profile a definitive biotype number because of the large number of combinations of positive and negative reactions defined by our tests. If, on the other hand, we were to adopt the device successfully used in the biotyping of Salmonella typhimurium (Duguid et al., 1975) we would, on the basis of ease of performance and discrimination achieved, choose the tests with dulcitol, sorbose, raffinose, and ornithine at the primary level to define 16 primary biotypes and, at the secondary level, the tests with rhamnose, lysine, motility, prototrophy, and perhaps, aesculin, to define full biotypes. However, more study of these tests will be required before any commitment to a two-tier system is made.

Patients with urinary-tract infection due to $E$. coli can be cured clinically and bacteriologically but often are subject to repeated infections. Because patient management varies according to whether recurrence is due to recrudescence by the same bacterium or reinfection by a new strain, it is necessary to define as accurately as possible the causative organism. Our initial aim, the establishment of a reliable biotyping system for epidemiological and clinical studies of strains of $E$. coli isolated from such patients, was achieved, but 
biotyping, as with any other differential typing system, has limitations when used alone, e.g., strains with the same biotype profile may be of diverse origin. Such a possibility may be overcome with an additional typing scheme used in conjunction with biotyping. In this preliminary paper, we have used partial serotyping, but we will report elsewhere on the very fine degree of strain discrimination achieved by the combined use of biotyping and the technique of resistotyping first introduced for E. coli by Elek and Higney (1970).

\section{SUMMARY}

We examined the results of tests with 22 substrates for their ability to discriminate a series of 917 strains of Escherichia coli collected from different sources. The tests with three of the substrates were discarded because of difficulties in performance or interpretation, and another nine substrates because they provided little discrimination. The tests used to obtain biotype profiles for strains were those for the fermentation of dulcitol, D-raffinose or sucrose or both, L-rhamnose and L-sorbose, the decarboxylation of L-lysine and L-ornithine, the hydrolysis of aesculin, motility, and prototrophy.

Observations on several series of cultures from different sources showed that biotype characters were stable in vivo and after storage on non-selective medium. The biotype profiles obtained were as reliable as partial $O$ serotyping for the routine subtyping of strains of $E$. coli isolated from the urine of patients with long-term urinary-tract infections and those from other sources in different patients. Biotyping and $\mathrm{O}$ serotyping used in conjunction offered a very fine degree of strain discrimination.

We thank Professor J. P. Duguid for much encouragement and advice throughout this investigation and Professor W. Brumfitt for the gift of some of the strains and information about them. We acknowledge the help of Dr Margaret I. Wilson in the early stages of this study.

\section{REFERENCES}

Àrr, M., PerènyI, T. AND Novàk, E. K. 1970. Sucrose and raffinose breakdown by Escherichia coli. Acta microbiol. hung., 17, 117.

Bettelheim, K. A. and Taylor, J. 1969. A study of Escherichia coli isolated from chronic urinary infection. J. med. Microbiol., 2, 225.

Bettelheim, K. A., Teoh-Chan, C. H., Chandler, M. E., O'Farrell, S. M., Rahamin, L., SHAw, E. J. AND SHOOTER, R. A. 1974. Further studies of Escherichia coli in babies after normal delivery. J. Hyg. Camb., 73, 277.

Buissière, J., Coynault, C. AND Le Minor, L. 1977. Étude des conditions d'expression du caractère raffinose chez les Escherichia coli et Salmonella. Annali Microbiol., $128,167$.

Butler, D. A., Lobregat, C. M. and Gavan, T. L. 1975. Reproducibility of the Analytab (API 20E) system. J. clin. Microbiol., 2, 322.

Cornelis, G., LuKe, R. K. J. AND Richmond, M. H. 1978. Fermentation of raffinose by lactose-fermenting strains of Yersinia enterocolitica and by sucrose-fermenting strains of Escherichia coli. J. clin. Microbiol., 7, 180.

CowAN, S. T. 1974. Cowan and Steel's manual for the identification of medical bacteria, 2nd ed., Cambridge. 
DAVIES, B. I. 1977. Biochemical typing of urinary Escherichia coli strains by means of the API 20E Enterobacteriaceae system. J. med. Microbiol., 10, 293.

Duguid, J. P., Anderson, E. S., Alfredsson, G. A., Barker, R. And Old, D. C. 1975 . A new biotyping scheme for Salmonella typhimurium and its phylogenetic significance. J. med. Microbiol., 8, 149.

Edberg, S. C., Pittman, S. AND Singer, J. M. 1977. Esculin hydrolysis by Enterobacteriaceae. J. clin. Microbiol., 6, 111.

Elek, S. D. AND Higney, L. 1970. Resistogram typing-a new epidemiological tool: application to Escherichia coli. J. med. Microbiol., 3, 103.

MaGalhães, M. AND VANCE, M. 1978. Hydrogen sulphide-positive strains of Escherichia coli from swine. J. med. Microbiol., 11, 211.

MeYNell, G. G. AND MEYNELl, E. 1965. Theory and practice in experimental bacteriology, $1 \mathrm{st}$ ed., Cambridge.

Miskin, A. AND EDBERG, S. C. 1978. Esculin hydrolysis reaction by Escherichia coli. J. clin. Microbiol., 7, 251.

Mushin, R. AND Ashburner, F. M. 1964. Ecology and epidemiology of coliform infections: II. The biochemical reactions and drug sensitivity of coliform organisms. Med. J. Aust., 1, 303.

Sakazaki, R., Tamura, K. AND Nakamura, A. 1974. Further studies on enteropathogenic Escherichia coli associated with diarrhoeal diseases in children and adults. Jap. J. med. Sci. Biol., $27,7$.

van Der WaAiJ, D., Speltie, T. M., Guinete, P. A. M. AND Agterberg, C. 1975. Serotyping and biotyping of 160 Escherichia coli strains: comparative study. J. clin. Microbiol., 1, 237. 